\title{
Association between manganese superoxide dismutase gene polymorphism and breast cancer risk: A meta-analysis of 17,842 subjects
}

\author{
GELING LIU ${ }^{1}$, GUOGUI SUN ${ }^{2}$, YADI WANG $^{3}$, DAN WANG ${ }^{4}$, WANNING HU ${ }^{2}$ and JUN ZHANG ${ }^{5}$ \\ ${ }^{1}$ Department of Endocrinology (Section I), Tangshan Workers Hospital, Tangshan 063000; ${ }^{2}$ Department of \\ Chemoradiation Therapy, Tangshan People's Hospital, Tangshan 063000; ${ }^{3}$ Department of Radiotherapy, \\ The Military General Hospital of Beijing PLA, Beijing 100700; ${ }^{4}$ Department of Library, Hebei Medical University, \\ Shijiazhuang 050017; ${ }^{5}$ Department of Radiotherapy, The Fourth Hospital of Hebei Medical University, \\ Shijiazhuang 050011, P.R. China
}

Received March 4, 2012; Accepted July 11, 2012

DOI: $10.3892 / \mathrm{mmr} .2012 .998$

\begin{abstract}
The aim of this meta-analysis was to explore the association between the manganese superoxide dismutase (MnSOD) gene polymorphism and breast cancer risk, and to investigate the interaction of this gene polymorphism with known risk factors for breast cancer. Crude odds ratios (ORs) with $95 \%$ confidence intervals (CIs) for breast cancer risk associated with co-dominant models [valine/alanine (Val/Ala) vs. Val/Val, Ala/Ala vs. Val/Val], a dominant model (Val/Ala + Ala/Ala vs. Val/Val) and a recessive model (Ala/Ala vs. Val/ $\mathrm{Ala}+\mathrm{Val} / \mathrm{Val}$ ) were statistically estimated. This meta-analysis included 8,102 breast cancer cases and 9,740 controls from 14 published case-control studies. The data revealed no significant association between the MnSOD polymorphism and the risk of developing breast cancer. However, upon subgroup analyses, the risk was significantly increased in premenopausal women with the dominant model of the MnSOD gene polymorphism (OR, 1.15; 95\% CI, 1.01-1.31). Statistically significant increased risks were also identified in women with the MnSOD genotypes containing the Ala allele who had a tobacco smoking history (OR, 1.17; 95\% CI, 1.02-1.34), a higher body mass index (OR, 1.26; 95\% CI, 1.02-1.56) or who used oral contraceptives (OR, 1.98; 95\% CI, 1.34-2.93). By contrast, there was no significant association between breast cancer risk and alcohol consumption and ethnicity. This meta-analysis demonstrated no statistically significant association between the MnSOD gene polymorphism and breast cancer susceptibility, except in premenopausal women with certain unhealthy lifestyle habbits.
\end{abstract}

Correspondence to: Dr Wanning Hu, Department of Chemoradiation Therapy, Tangshan People's Hospital, Tangshan, Hebei 063000, P.R. China

E-mail: wanning_hu2008@sina.com

Key words: manganese superoxide dismutase, breast cancer, gene polymorphism, case-control study, reactive oxygen species, oxidative stress

\section{Introduction}

Breast cancer is the most common malignant disease among women worldwide. Breast cancer accounted for more than 1.3 million new cases and 464,000 mortalities in 2007 (1). A higher risk of breast cancer is associated with individuals who are older, have a family history of breast cancer, are overweight or obese following menopause, have never had children, have recently used oral contraceptives, had their first child after age 30, have gene mutations (including BRCA1 and BRCA2 mutation), have high breast tissue density and have used postmenopausal hormone therapy. However, living a healthy lifestyle, including maintaining a healthy body weight, increasing physical activity and minimizing alcohol intake, may reduce breast cancer risk (1). To date, practical screening to detect the early stages of breast cancer and significant advances in treatment have significantly reduced breast cancer mortality; however, many women still develop metastatic disease and ultimately succumb to the disease. Therefore, there is an urgent requirement to develop more aggressive and useful strategies to identify high-risk populations for the early detection and prevention of breast cancer.

Risk factors contribute to breast cancer development through multiple genetic or epigenetic alterations (1), including the activation of oncogenes or the silencing of tumor suppressor genes $(1,2)$. To date, a large body of evidence has accumulated regarding these gene alterations that are associated with mammary gland carcinogenesis, although the precise mechanism underlying breast cancer development remains to be defined. For example, manganese superoxide dismutase (MnSOD) is essential for mammalian cell vitality and has been considered as a tumor suppressor gene as oxidative stress and mitochondrial DNA damage play a significant role in breast cancer carcinogenesis (2). The MnSOD gene is localized on chromosome 6q25.3 and contains 4 introns and 5 exons, with at least 2 functionally validated single nucleotide polymorphisms in the amino acid codons at 9 and 16. The MnSOD protein is synthesized in the cytoplasm and then transported into the mitochondria via $\mathrm{N}$-terminal mitochondrial targeting sequences. A common 
polymorphism of MnSOD is Val16Ala (rs4880) at the 9-amino acid upstream of this cleavage site, a substitution of thymine to cytosine ( $\mathrm{T}$ to $\mathrm{C}$ ) at nucleotide 47 , resulting in the encoded amino acid from valine (Val, GTT) to alanine (Ala, GCT) on the 16th residue of the 24-amino acid signal sequence $(3,4)$. This particular polymorphism has been designated as the MnSOD Val9Ala (rs4880) polymorphism (4). The Val variant is predicted to form a $\beta$-sheet structure, while the Ala variant results in an $\alpha$-helical conformation. The Ala variant leads to a decreased transport rate into the inner mitochondrial membrane and therefore, reduces MnSOD enzymatic activity compared to the Val variant. Inefficient MnSOD protein in the mitochondria may leave the cell vulnerable to oxidative damage without its full defense against superoxide radicals, resulting in protein oxidation and DNA mutations. There is increasing evidence demonstrating that the MnSOD gene polymorphism is a risk factor for several types of malignancies, including breast $(5,6)$, lung (7), bladder (8), colorectal (9) and prostate $(10,11)$ cancer.

In breast cancer, a number of individual studies have been conducted to explore the association between the MnSOD gene polymorphism and breast cancer susceptibility; however, the results remain inconclusive. This may be due to the possibly small effect of this gene polymorphism on breast cancer risk, or the relatively small sample sizes of each published study. Thus, in the present study, we performed a meta-analysis of the published data to obtain a more precise estimation of this gene polymorphism as a risk factor for breast cancer.

\section{Materials and methods}

Identification and eligibility of relevant studies. In this study, we attempted to include all case-control studies published to date that have examined the association between the MnSOD gene polymorphism and breast cancer. We searched the PubMed database using the search terms 'manganese superoxide dismutase', 'MnSOD', 'polymorphism(s)' and 'breast cancer'. Additional articles were identified from the references of original studies or reviews. Our meta-analysis included only full-text publications written in English, and we did not define an inclusion criteria for a minimum number of subjects. In addition, in case of multiple studies published using the same group of subjects, we only selected the largest and/or the most recent publication.

Inclusion and exclusion criteria. In this meta-analysis, the selected publications had to meet the following criteria: i) have individuals with a pathologically confirmed diagnosis of breast cancer and confirmed control individuals which were free of any cancer; ii) be an independent case-control or cohort study that quantitatively evaluated the association between breast cancer risk and MnSOD gene polymorphism; iii) have sufficient data to calculate odds ratios (ORs) with $95 \%$ confidence intervals (CIs); and iv) have sufficient subgroup information for more detailed analyses. By contrast, the major exclusion criteria were: i) studies that had no control population, ii) studies that had no available genotype frequency, or iii) studies that were duplicated from a previous study.

Data extraction. We followed a standard protocol for data extraction. Two independent investigators extracted data and then reached a consensus on all of the items through discussion. In the event when no consensus could be reached, a third investigator was then consulted to resolve the dispute, and a final decision was formulated by the majority. The following information was recorded for each publication: first author, publication date, ethnicity of subjects, criteria for matching controls, total number of cases and controls, genotype frequencies of the cases and controls (e.g., Val/Val, Val/Ala, Ala/Ala) and result of the Hardy-Weinberg equilibrium calculations.

Statistical analysis. Crude ORs with $95 \%$ CIs were used to estimate the relative risk of breast cancer associated with MnSOD gene polymorphism. For all subjects, we evaluated the risk of Val/Ala vs. Val/Val, Ala/Ala vs. Val/Val, Ala/Ala vs. $\mathrm{Val} / \mathrm{Ala}+\mathrm{Val} / \mathrm{Val}$, and $\mathrm{Val} / \mathrm{Ala}+$ Ala/Ala vs. Val/Val, assuming 2 co-dominant models, 1 recessive model, and 1 dominant model, respectively. An online Chi-square $\left(\chi^{2}\right)$ test program (http://ihg2.helmholtz-muenchen.de/cgi-bin/hw/ hwa1.pl) was used to determine whether the reported genotype distribution in the control population conformed to the Hardy-Weinberg equilibrium. $\mathrm{P}<0.05$ was considered to indicate a statistically significant difference.

Subgroup analyses were then conducted for factors related to menopausal status, lifestyle and ethnicity. Heterogeneity was determined using the $\chi^{2}$-based Q-test using the formula: $\mathrm{Q}=\sum$ weight $\left._{\mathrm{i}} \mathrm{x}\left(\operatorname{lnOR}_{\mathrm{MH}}-\operatorname{lnOR}\right)_{\mathrm{i}}\right)^{2}$, where weight $\mathrm{i}_{\mathrm{i}}=1 /$ variance $_{\mathrm{i}}$. $\mathrm{P}>0.10$ for the $\mathrm{Q}$ test was considered to indicate a lack of heterogeneity among the studies. Furthermore, the fixedeffects model (Mantel-Haenszel) and the random-effects model (DerSimonian and Laird) were also used to combine values from each of the studies. Use of the random-effects model was more appropriate when heterogeneity was present. If the controls in the studies were found to not be in the Hardy-Weinberg equilibrium, sensitivity analysis was performed with and without these studies to test the robustness of the findings. Similarly, sensitivity analysis was also conducted by omitting each study in turn to identify potential outliers. Potential publication bias was estimated using Begg's funnel plots and Egger's test, in which an asymmetric plot suggested a possible publication bias and $\mathrm{P}<0.05$ indicated a statistically significant publication bias. All statistical analyses were performed using Review Manage version 4.2 (Oxford, England) and STATA version 11.0 (Stata Corporation, College Station, TX, USA). All P-values were two-sided.

\section{Results}

Study characteristics. The main characteristics of this meta-analysis are shown in Table I. We identified 14 eligible studies that were published between 1999 and 2009 and consisted of 8,102 breast cancer cases and 9,740 controls. Sample sizes for these 14 studies ranged from 187 to 3,837 . Seven studies had been conducted on mixed-ethnicity populations, 5 studies on Caucasian and 2 studies on Asian populations. All studies, except 4, indicated that the distribution of the genotypes in the controls was consistent with the Hardy-Weinberg equilibrium. The controls in all studies were primarily healthy and were matched for age to the breast cancer cases. 
Table I. Characteristics of the published studies included in the meta-analysis.

\begin{tabular}{|c|c|c|c|c|c|c|c|c|c|c|c|}
\hline \multirow[b]{2}{*}{ Authors/(Refs.) } & \multirow[b]{2}{*}{ Year } & \multirow[b]{2}{*}{ Ethnicity } & \multirow[b]{2}{*}{ Source } & \multirow[b]{2}{*}{ Case/control } & \multicolumn{3}{|c|}{ Case } & \multicolumn{3}{|c|}{ Control } & \multirow[b]{2}{*}{ HWE } \\
\hline & & & & & VV & VA & AA & VV & VA & AA & \\
\hline Ambrosone et al (12) & 1999 & Mixed & PB & $266 / 295$ & 39 & 137 & 90 & 63 & 169 & 63 & $0.012^{\mathrm{a}}$ \\
\hline Mitrunen et al (5) & 2001 & Caucasian & $\mathrm{HB}$ & $479 / 482$ & 124 & 255 & 100 & 153 & 231 & 98 & 0.526 \\
\hline Egan et al (13) & 2003 & Mixed & PB & $470 / 497$ & 102 & 250 & 118 & 130 & 240 & 127 & 0.446 \\
\hline Cai et al (6) & 2004 & Asian & PB & $1125 / 1197$ & 831 & 266 & 28 & 844 & 290 & 23 & 0.741 \\
\hline Millikan et al (14) & 2004 & Mixed & $\mathrm{PB}$ & $2025 / 1812$ & 532 & 1053 & 440 & 462 & 943 & 407 & 0.075 \\
\hline Tamimi et al (15) & 2004 & Mixed & HB & $968 / 1205$ & 255 & 468 & 245 & 297 & 612 & 296 & 0.584 \\
\hline Bergman et al (16) & 2005 & Caucasian & $\mathrm{PB}$ & $118 / 174$ & 12 & 73 & 33 & 43 & 88 & 43 & 0.879 \\
\hline Cheng et al (17) & 2005 & Asian & $\mathrm{PB}$ & $469 / 739$ & 343 & 115 & 11 & 545 & 183 & 11 & 0.322 \\
\hline Gaudet et al (18) & 2005 & Mixed & PB & $1034 / 1084$ & 253 & 511 & 270 & 264 & 539 & 281 & 0.862 \\
\hline Kocabas et al (19) & 2005 & Caucasian & $\mathrm{PB}$ & $84 / 103$ & 23 & 32 & 29 & 25 & 40 & 38 & $0.032^{\mathrm{a}}$ \\
\hline Slanger et al (20) & 2006 & Caucasian & $\mathrm{PB}$ & $614 / 1080$ & 144 & 318 & 152 & 263 & 528 & 289 & 0.477 \\
\hline Bica et al (21) & 2007 & Mixed & HB & $100 / 370$ & 29 & 56 & 15 & 94 & 252 & 24 & $<0.001^{\mathrm{a}}$ \\
\hline Bica et al (22) & 2009 & Mixed & $\mathrm{HB}$ & $100 / 372$ & 15 & 29 & 56 & 26 & 94 & 252 & $<0.001^{\mathrm{a}}$ \\
\hline Eras-Erdogan et al (23) & 2009 & Caucasian & $\mathrm{PB}$ & $250 / 330$ & 107 & 113 & 30 & 150 & 141 & 39 & 0.508 \\
\hline
\end{tabular}

VV, Val/Val; VA, Val/Ala; AA, Ala/Ala; HB, hospital-based control; PB, population-based control; HWE, Hardy-Weinberg equilibrium; ${ }^{\mathrm{a}} \mathrm{P}<0.05$.

Table II. Odds ratios for MnSOD genotypes and breast cancer according to menopausal status.

\begin{tabular}{|c|c|c|c|c|c|c|c|c|}
\hline MnSOD genotypes & Case & Control & OR & $95 \% \mathrm{CI}$ & $\chi^{2 a}$ & P-value & Z-value ${ }^{b}$ & P-value ${ }^{b}$ \\
\hline \multicolumn{9}{|l|}{ Premenopausal women } \\
\hline Val/Ala vs. Val/Val & 1215 & 1409 & 1.09 & $0.95-1.25$ & 6.35 & 0.50 & 1.25 & 0.21 \\
\hline Ala/Ala vs. Val/Val & 565 & 652 & 1.09 & $0.93-1.28$ & 8.80 & 0.27 & 1.02 & 0.31 \\
\hline Ala/Ala vs. Val/Val + Val/Ala & 655 & 652 & 1.06 & $0.85-1.32$ & 15.22 & $0.03^{\mathrm{c}}$ & 0.52 & 0.60 \\
\hline Val/Ala + Ala/Ala vs. Val/Val & 1781 & 1977 & 1.15 & $1.01-1.31$ & 4.06 & 0.77 & 2.13 & 0.03 \\
\hline \multicolumn{9}{|l|}{ Postmenopausal women } \\
\hline Val/Ala vs. Val/Val & 1790 & 1838 & 1.11 & $0.91-1.35$ & 17.22 & $0.02 b$ & 1.02 & 0.31 \\
\hline Ala/Ala vs. Val/Val & 839 & 872 & 1.02 & $0.89-1.16$ & 5.33 & 0.62 & 0.29 & 0.77 \\
\hline Ala/Ala vs. Val/Val + Val/Ala & 839 & 872 & 1.00 & $0.90-1.12$ & 9.76 & 0.20 & 0.06 & 0.95 \\
\hline Val/Ala + Ala/Ala vs. Val/Val & 2629 & 2710 & 1.03 & $0.92-1.14$ & 10.98 & 0.14 & 0.46 & 0.65 \\
\hline
\end{tabular}

${ }^{\mathrm{a}}$ Test for heterogeneity. ${ }^{\mathrm{b}} \mathrm{Test}$ for overall effect. ${ }^{\mathrm{c}} \mathrm{A}$ random-effects model was used when for heterogeneity the $\mathrm{P}<0.10$ value; otherwise, a fixed-effects model was used. MnSOD, manganese superoxide dismutase; OR, odds ratio.

Association between MnSOD gene polymorphism and breast cancer risk. To determine the association between the MnSOD gene polymorphism and breast cancer risk, we recalculated the ORs and their corresponding 95\% CIs from the 14 studies (Fig. 1). However, there was no significant association between the MnSOD gene polymorphism and breast cancer risk analyzed in the different genetic models. As shown in Fig. 1, neither variant heterozygotes (Val/Ala) nor variant homozygotes (Ala/Ala) led to an increased risk of breast cancer compared to the wild-type Val/Val homozygotes (Val/Ala vs. Val/Val: OR, 1.04; 95\% CI, 0.93-1.17; Ala/Ala vs. Val/Val: OR, 1.12; 95\% CI, 0.95-1.33). Furthermore, there was no significant association between the MnSOD gene polymorphism and breast cancer risk in either the recessive model (Ala/Ala vs. Val/Ala + Val/Val: OR, 1.06; 95\% CI, 0.93-1.20) or the dominant model (Val/Ala + Ala/Ala vs. Val/Val: OR, 1.06; 95\% CI, 0.94-1.18).

However, in the subgroup analysis of menopausal status using the dominant model, a statistically significant increased risk of breast cancer was found in premenopausal women (Val/Ala + Ala/Ala vs. Val/Val: OR, 1.15; 95\% CI, 1.01-1.31). However, there was no significant association identified in postmenopausal women among the different genetic models (Fig. 2; Table II). Additional analysis was conducted to evaluate the association of the MnSOD gene polymorphism with breast cancer risk stratified by lifestyle factors (Table III). We found that there was significant evidence demonstrating that a history of smoking tobacco was associated with an increased risk of breast cancer in carriers of the Ala allele (OR, 1.17; 95\% CI, 1.02-1.34). The OR was significant for women who 
$\mathbf{A}$

\begin{tabular}{|c|c|c|c|c|c|c|}
\hline $\begin{array}{l}\text { Study } \\
\text { or sub-cotegory }\end{array}$ & $\begin{array}{l}\text { Case } \\
\mathrm{nN}\end{array}$ & $\begin{array}{l}\text { Control } \\
\mathrm{nN}\end{array}$ & $\begin{array}{c}\text { OR (random) } \\
95 \% \text { al }\end{array}$ & $\begin{array}{c}\text { Weight } \\
\%\end{array}$ & & $\begin{array}{c}\text { OR (random) } \\
95 \% \text { Cl }\end{array}$ \\
\hline Ambrosone C8 1999 & $137 / 176$ & $169 / 232$ & $\rightarrow-$ & 4. 38 & 1.31 & {$[0.83,2.07]$} \\
\hline Mtrunen K 2001 & $255 / 379$ & $231 / 384$ & & 7.79 & 1.36 & {$[1.01,1.83\}$} \\
\hline Eagn roM 2003 & $250 / 352$ & $240 / 370$ & 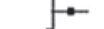 & 7.29 & 1.33 & {$[0.97,1.82]$} \\
\hline $\operatorname{CaiO} 2004$ & $266 / 1097$ & $290 / 1134$ & & 11.50 & 0.93 & $10.77,1.131$ \\
\hline Miskan RC 2004 & $1053 / 1585$ & $943 / 1405$ & & 13.18 & 0.97 & $(0.83,1.131$ \\
\hline Tanini RM 2004 & $468 / 723$ & $612 / 909$ & & 10.92 & 0.89 & $10.72,1.091$ \\
\hline Bergnan M 2005 & $73 / 85$ & $88 / 131$ & & 2.13 & 2.97 & $(1.46,6.05\}$ \\
\hline Cheng IC 2005 & $115 / 458$ & $183 / 728$ & & 8.61 & 1.00 & {$[0.76,1.31]$} \\
\hline Gaudet Mu 2005 & $511 / 764$ & $539 / 803$ & & 10.74 & 0.99 & $(0.80,1.221$ \\
\hline Kocabas NA 2005 & $32 / 55$ & $40 / 65$ & & 2.02 & 0.87 & $(0.42,1.81\}$ \\
\hline Slanget TE 2006 & $318 / 462$ & $528 / 791$ & & 9.41 & 1.10 & {$[0.86,1.41]$} \\
\hline Bica $C O 2007$ & $56 / 85$ & $252 / 346$ & & 3.75 & 0.72 & {$[0.43,1.20]$} \\
\hline Bica CO 2009 & $29 / 44$ & $94 / 120$ & & 1.90 & 0.53 & {$[0.25,1.14]$} \\
\hline Eras-Erdogan N 2009 & $113 / 220$ & $141 / 291$ & & 6.37 & 1.12 & {$[0.79,1.59]$} \\
\hline Tetal (95\% C) & & 7709 & & 100.00 & 1.04 & \\
\hline \multirow{2}{*}{\multicolumn{7}{|c|}{$\begin{array}{l}\text { Total everts: } 3676 \text { (Case), } 4350 \text { (Cortro) } \\
\text { Test for heterogenety. Chi? } 24.67 \text {, dt }=13(P=0.03), 17=47.3 \% \\
\text { Test for overal effect: } Z=0.76(P=0.45)\end{array}$}} \\
\hline & & & & & & \\
\hline \multirow{2}{*}{\multicolumn{5}{|c|}{10}} & & \\
\hline & & & & & & \\
\hline
\end{tabular}

B

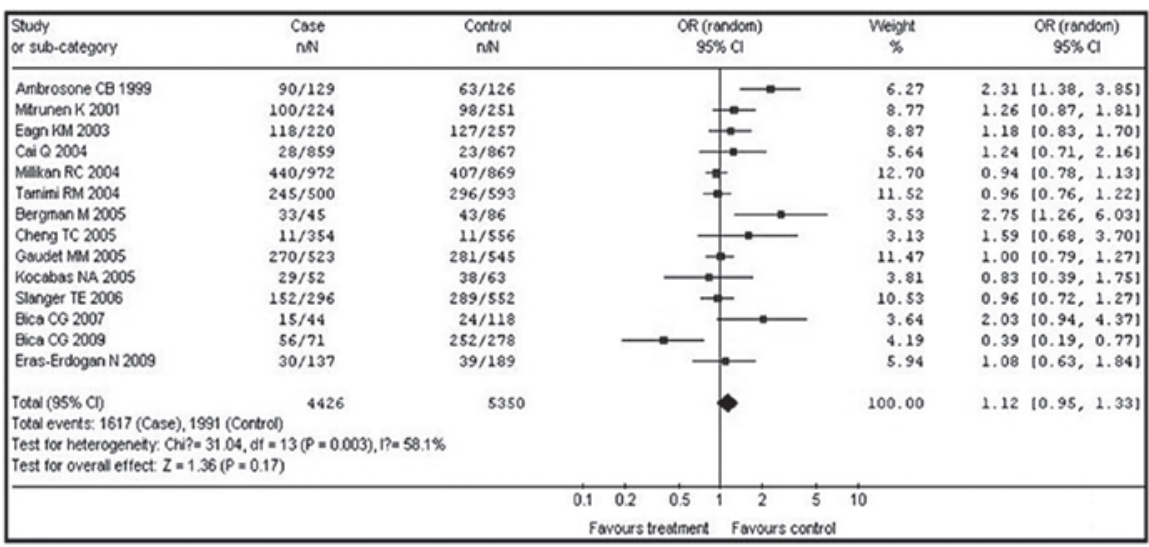

C

\begin{tabular}{|c|c|c|c|c|c|}
\hline $\begin{array}{l}\text { Soluy } \\
\text { os sub-costegary }\end{array}$ & $\begin{array}{l}\text { case } \\
\text { nN }\end{array}$ & $\begin{array}{c}c \text { control } \\
\mathrm{nNN}\end{array}$ & 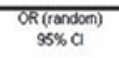 & $\begin{array}{l}\text { Wegrt } \\
\%\end{array}$ & $\begin{array}{l}\text { OR (romerban) } \\
95 \% a\end{array}$ \\
\hline 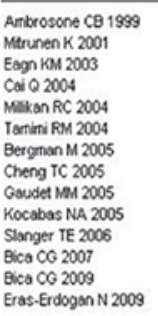 & 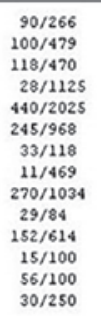 & 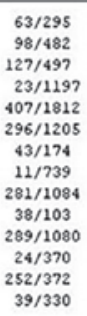 & $\because-$ & $\begin{aligned} 6.81 \\
8.39 \\
9.03 \\
3.97 \\
13.73 \\
12.18 \\
4.29 \\
1.99 \\
12.23 \\
3.52 \\
11.04 \\
2.84 \\
5.41 \\
4.57\end{aligned}$ & 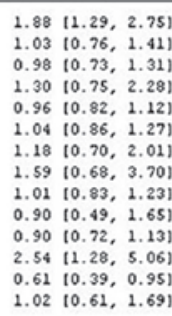 \\
\hline \multicolumn{3}{|c|}{ 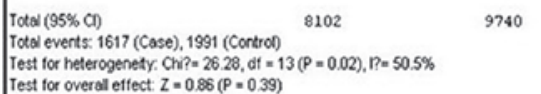 } & 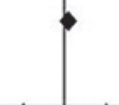 & 100.00 & $1.06\{0.93,1.20\}$ \\
\hline
\end{tabular}

D

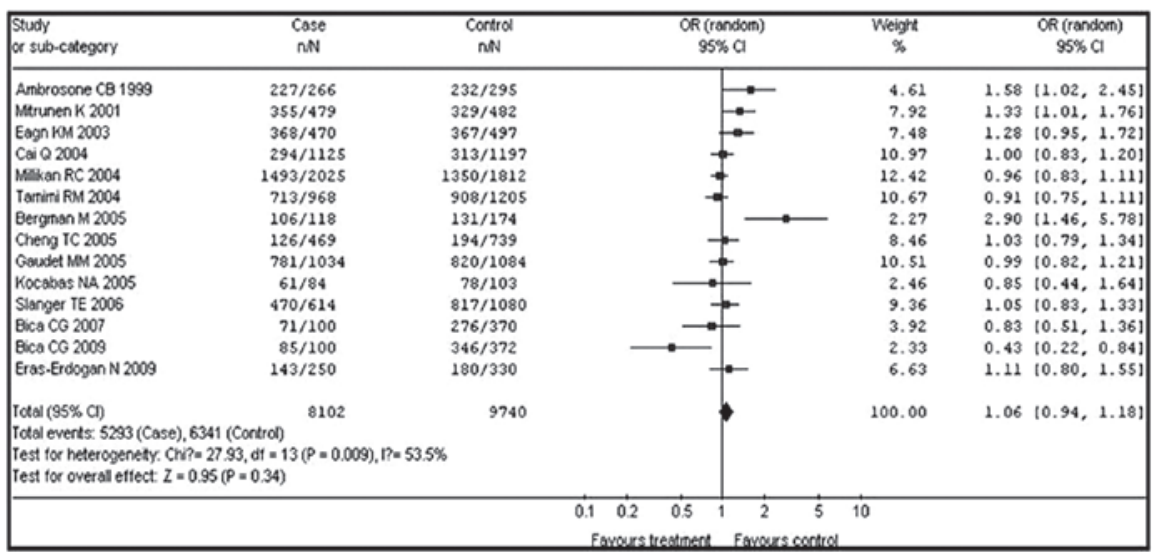

Figure 1. Forest plot odds ratios with $95 \% \mathrm{CI}$ between the MnSOD gene polymorphism and breast cancer risk. (A) Val/Ala vs. Val/Val. (B) Ala/Ala vs. Val/Val. (C) Ala/Ala vs. Val/Val + Val/Ala. (D) Val/Ala + Ala/Ala vs. Val/Val. OR, odds ratio; MnSOD, manganese superoxide dismutase. 
Table III. Correlation between MnSOD genotypes and breast cancer according to lifestyle.

\begin{tabular}{|c|c|c|c|c|c|c|c|c|}
\hline \multirow[b]{2}{*}{ Lifestyle factors } & \multicolumn{8}{|c|}{ MnSOD genotypes (Val/Ala + Ala/Ala vs. Val/Val) } \\
\hline & Case & Control & OR & $95 \% \mathrm{CI}$ & $\chi^{2 \mathrm{a}}$ & P-value ${ }^{a}$ & Z-value ${ }^{b}$ & P-value ${ }^{b}$ \\
\hline \multicolumn{9}{|c|}{ History of smoking } \\
\hline Never & 1156 & 1337 & 1.07 & $0.84-1.36$ & 11.32 & $0.05^{\mathrm{c}}$ & 0.61 & 0.54 \\
\hline Ever & 1450 & 1798 & 1.17 & $1.02-1.34$ & 5.00 & $0.08^{\mathrm{c}}$ & 2.18 & 0.03 \\
\hline \multicolumn{9}{|c|}{ Alcohol consumption } \\
\hline Never & 834 & 821 & 0.97 & $0.80-1.18$ & 2.32 & 0.31 & 0.27 & 0.78 \\
\hline Ever & 467 & 942 & 1.42 & $0.89-2.26$ & 7.47 & $0.02^{\mathrm{c}}$ & 1.46 & 0.14 \\
\hline \multicolumn{9}{|c|}{ Body mass index $\left(\mathrm{kg} / \mathrm{m}^{2}\right)$} \\
\hline$<25$ & 389 & 471 & 0.94 & $0.78-1.15$ & 0.91 & 0.63 & 0.58 & 0.56 \\
\hline$\geq 25$ & 363 & 331 & 1.26 & $1.02-1.56$ & 2.34 & 0.31 & 2.12 & 0.03 \\
\hline \multicolumn{9}{|c|}{ Oral contraceptives } \\
\hline Never & 376 & 331 & 1.13 & $0.85-1.51$ & 0.45 & 0.50 & 0.83 & 0.40 \\
\hline Ever & 226 & 221 & 1.98 & $1.34-2.93$ & 1.26 & 0.26 & 3.45 & 0.0006 \\
\hline
\end{tabular}

${ }^{a}$ Test for heterogeneity. ${ }^{\mathrm{b}}$ Test for overall effect. ${ }^{\mathrm{c}} \mathrm{A}$ random-effects model was used when the P-value for heterogeneity was <0.10; otherwise, a fixed-effects model was used. MnSOD, manganese superoxide dismutase; OR, odds ratio.

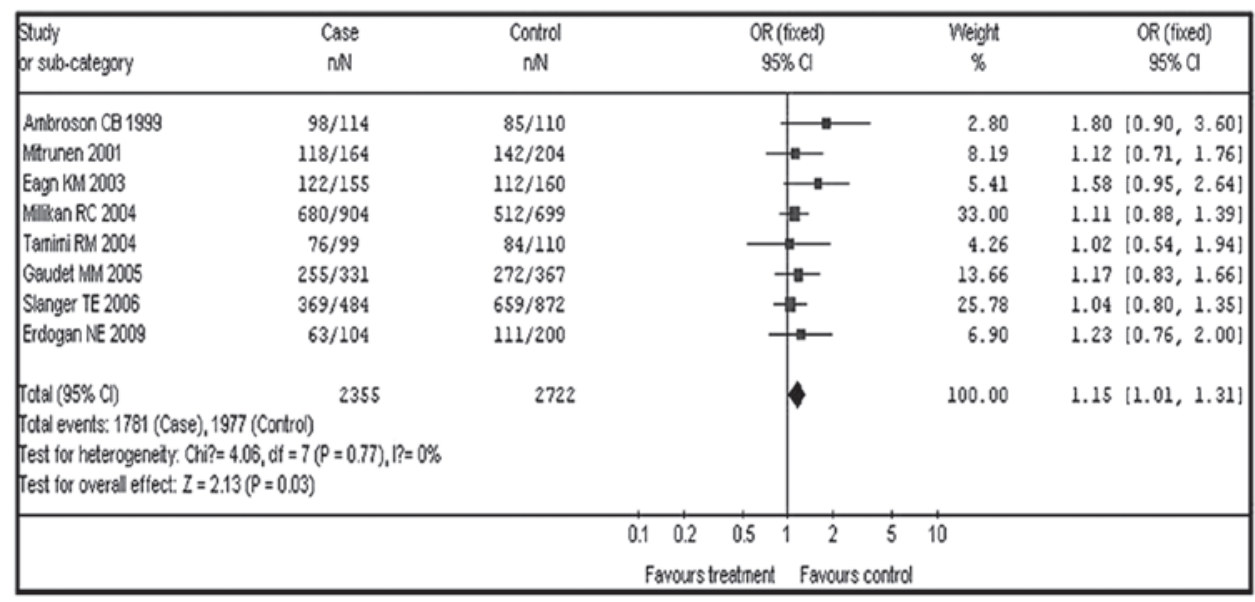

Figure 2. Forest plot odds ratios with 95\% CI between the MnSOD gene polymorphism and breast cancer risk in premenopausal women for the dominant model (Val/Ala + Ala/Ala vs. Val/Val). OR, odds ratio; MnSOD, manganese superoxide dismutase.

carried the Val/Ala or Ala/Ala genotypes and had a body mass index $\geq 25 \mathrm{~kg} / \mathrm{m}^{2}$ (OR, 1.26; $\left.95 \% \mathrm{CI}, 1.02-1.56\right)$. Moreover, a significant risk of breast cancer was identified in women who carried the MnSOD Val/Ala or Ala/Ala genotypes and used oral contraceptives (OR, 1.98; 95\% CI, 1.34-2.93). By contrast, there was no significant effect of alcohol consumption on breast cancer risk in women carrying the Ala allele (OR, 1.42; 95\% CI, 0.89-2.26). In addition, when the controls were stratified by ethnicity, there was no significant association of the MnSOD gene polymorphism with breast cancer risk observed among Caucasian, mixed ethnicity or Asian women for any comparison model (Table IV).

Analysis of sensitivity for association of MnSOD gene polymorphism with breast cancer risk. To analyze the sensitivity of the association between the MnSOD gene polymorphism and breast cancer risk, we identified 4 studies $(12,19,21,22)$ that did not follow the Hardy-Weinberg equilibrium in the distribution of the genotype among the controls. However, the significance of the corresponding recalculated ORs and 95\% CIs was not changed regardless of whether these studies were included in the analysis [co-dominant models (Val/Ala vs. Val/Val: OR, 1.01; 95\% CI, 0.93-1.09; Ala/Ala vs. Val/Val: OR, 1.06; 95\% CI, 0.90-1.26), recessive model (Ala/Ala vs. Val/Ala + Val/Val: OR, 1.00; 95\% CI, 0.92-1.09) and dominant model (Val/Ala + Ala/Ala vs. Val/Val: OR, 1.04; 95\% CI, 0.90-1.18)]. Furthermore, upon sensitivity analyses stratified by menopausal status, lifestyle factors and ethnicity, pooled estimates for all genetic models were insensitive to the removal of individual studies, and the corresponding pooled ORs were not substantially changed (data not shown), indicating that the results were statistically robust. 
Table IV. Odds ratios for MnSOD genotypes and breast cancer according to ethnicity.

\begin{tabular}{lrrrrrrrr}
\hline MnSOD genotypes & Case & Control & OR & $95 \%$ CI & $\chi^{2 a}$ & P-value $^{\mathrm{a}}$ & Z-value $^{\mathrm{b}}$ & P-value $^{\mathrm{b}}$ \\
\hline Caucasian & & & & & & & & \\
Val/Ala vs. Val/Val & 791 & 1028 & 1.26 & $0.98-1.63$ & 8.27 & $0.08^{\mathrm{c}}$ & 1.80 & 0.07 \\
Ala/Ala vs. Val/Val & 344 & 507 & 1.11 & $0.92-1.35$ & 7.20 & 0.13 & 1.10 & 0.27 \\
Ala/Ala vs. Val/Val + Val/Ala & 344 & 507 & 0.97 & $0.83-1.13$ & 1.20 & 0.88 & 0.41 & 0.68 \\
Val/Ala + Ala/Ala vs. Val/Val & 1135 & 1535 & 1.23 & $0.95-1.58$ & 9.28 & $0.05^{\mathrm{c}}$ & 1.58 & 0.11 \\
Mixed & & & & & & & & \\
Val/Ala vs. Val/Val & 2504 & 2849 & 0.98 & $0.89-1.08$ & 9.83 & 0.13 & 0.44 & 0.66 \\
Ala/Ala vs. Val/Val & 1234 & 1450 & 1.08 & $0.84-1.38$ & 21.95 & $0.001^{\mathrm{c}}$ & 0.61 & 0.55 \\
Ala/Ala vs. Val/Val + Val/Ala & 1234 & 1450 & 1.08 & $0.89-1.32$ & 22.84 & $0.0009^{\mathrm{c}}$ & 0.79 & 0.43 \\
Val/Ala + Ala/Ala vs. Val/Val & 3738 & 4299 & 0.99 & $0.85-1.17$ & 14.41 & $0.03^{\mathrm{c}}$ & 0.07 & 0.95 \\
Asian & & & & & & & & \\
Val/Ala vs. Val/Val & 381 & 473 & 0.95 & $0.82-1.12$ & 0.17 & 0.68 & 0.60 & 0.50 \\
Ala/Ala vs. Val/Val & 39 & 43 & 1.34 & $0.84-2.14$ & 0.22 & 0.64 & 1.22 & 0.22 \\
Ala/Ala vs. Val/Val + Val/Ala & 39 & 43 & 1.38 & $0.87-2.20$ & 0.15 & 0.70 & 1.36 & 0.17 \\
Val/Ala + Ala/Ala vs. Val/Val & 420 & 507 & 1.01 & $0.87-1.17$ & 0.04 & 0.84 & 0.13 & 0.90 \\
\hline
\end{tabular}

${ }^{\mathrm{a}}$ Test for heterogeneity. ${ }^{\mathrm{b}}$ Test for overall effect. ${ }^{\mathrm{c}} \mathrm{A}$ random-effects model was used when the $\mathrm{P}<0.10$ for heterogeneity; otherwise, a fixed-effects model was used. MnSOD, manganese superoxide dismutase; OR, odds ratio.

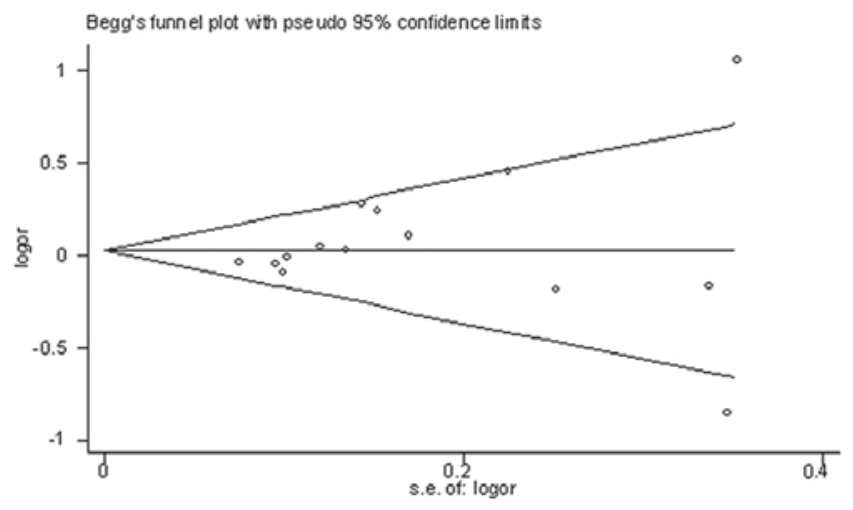

Figure 3. Funnel plot for odds ratios of dominant model in overall association.

Analysis of bias for the published data. Next, we performed statistical analysis for any bias produced in these publications and the shapes of the Begg's funnel plots demonstrated no evident asymmetry for any of the different models in the overall analysis (Fig. 3). The results of Egger's test also indicated no evidence of publication bias in any comparison model $(\mathrm{P}=0.39$ for Val/Ala vs. Val/Val, $\mathrm{P}=0.37$ for Ala/Ala vs. Val/Val, $\mathrm{P}=0.56$ for Ala/Ala vs. Val/Ala + Val/Val, $\mathrm{P}=0.32$ for $\mathrm{Val} / \mathrm{Ala}$ + Ala/Ala vs. Val/Val). Furthermore, the Begg's funnel plots and Egger's test did not reveal any evidence of asymmetry in the 3 other subgroups (data not shown).

\section{Discussion}

In the present study, we performed a meta-analysis of 14 published studies in order to determine the association between the MnSOD gene polymorphism and breast cancer risk. Our data demonstrated that there was no significant association between polymorphisms of the MnSOD gene and breast cancer risk. However in subgroup analyses, the risk was significantly increased in premenopausal women with the dominant model of the MnSOD gene polymorphism. It was identified that there was a statistically significant increased risk in women with the Ala allele of the MnSOD gene who had a history of smoking tobacco, had a higher body mass index or used oral contraceptives. By contrast, there was no significant association between breast cancer risk and the dominant model of the MnSOD gene polymorphism and alcohol consumption or ethnicity groups. In conclusion, the present study demonstrates no statistically significant association between the MnSOD gene polymorphism and breast cancer susceptibility. In subgroup analyses, the MnSOD gene polymorphism increased breast cancer risk in premenopausal women with particular lifestyles. Future studies should focus on the function of the MnSOD protein in breast cancer.

MnSOD is a mitochondrial enzyme which converts the superoxide radical $\mathrm{O}_{2}$ - into $\mathrm{H}_{2} \mathrm{O}_{2}$, and then subsequently into water and oxygen under the combined action of glutathione peroxidase and catalase. Thus, MnSOD is a signficant antioxidant enzyme in human cells. Previous studies have demonstrated that low levels of MnSOD expression lead to an increase in reactive oxygen species (ROS) in the mitochondria. These can damage DNA, proteins and lipids, and also increase the instability of the genome, causing the transformation of normal cells $(24,25)$. Other studies have revealed that MnSOD expression is absent or reduced in breast (26), prostate (27) or lung (28) cancers. These studies indicate that the alteration of MnSOD expression in different types of cancer. However, the current study does not demonstrate any statistical association between the MnSOD gene polymorphism and breast cancer risk, although data from subgroup analyses revealed a slight association between the polymorphism and breast cancer risk 
in premenopausal women with particular lifestyles. The reason for this is unclear, although previous data have demonstrated that the MnSOD gene polymorphism affects the normal localization of the MnSOD protein in the mitochondria, and therefore, reduces the MnSOD enzymatic activity and leads to a reduced ability to remove ROS, increasing tumor formation (29). Zhao et al (30) demonstrated that ROS play a role in regulating cell proliferation concerning signal transduction pathways. Therefore, a high number of the Ala variant of the MnSOD gene may result in a high risk of developing breast cancer, particularly when cells are exposed to higher ROS stress. One explanation for the lack of an association between the MnSOD gene polymorphism and breast cancer risk could be that other mitochondrial enzymes may compensate the activity of MnSOD to maintain normal levels of ROS activity in the cells. However, the effects of MnSOD mutations on breast cancer risk and the mechanistic basis for these effects requires further examination.

Meta-analysis is a powerful and useful tool to combine the data from several studies that address a set of related research hypotheses, e.g., the study of gene polymorphisms for cancer risk. The advantage of this analysis is it's ability to combine several studies to achieve a high number of cases, and therefore, be less affected by local findings than single studies. Meta-analysis also makes it possible to identify publication bias, help researchers to investigate a large number of individuals and estimate the effect of a certain genetic factor on cancer risk. Although a number of studies have reported an important role of MnSOD gene polymorphism in breast cancer risk, this meta-analysis did not demonstrate any association.

However, in the subgroup analyses, we found a significantly increased risk in premenopausal women with the Ala variant of the MnSOD gene. However, it is unclear why the Ala variant of MnSOD gene contributed to breast cancer risk among premenopausal women. Previous studies have revealed that in other malignancies MnSOD overexpression reduced levels of ROS and in turn decreased the doubling time of osteosarcoma SaOS2 cells and plating efficiency $(31,32)$. MnSOD overexpression inhibited the malignant phenotype and growth of SV40 human fibroblasts (33), malignant melanoma tumors (34) and gliomas (35). These data may indirectly suggest that ROS may play a more significant role in breast carcinogenesis among younger women than that of postmenopausal women. Furthermore, although Slanger et al (20) did not identify a difference in ORs of MnSOD Ala/Ala and Ala/Val genotypes in cigarette smokers, this meta-analysis did reveal that women who carried at least one copy of the Ala allele and who smoked were at higher risk of developing breast cancer than that of non-carriers. Mitrunen et al (5) demonstrated that women who consumed alcohol and who had the Val/Ala or Ala/Ala genotype had a 2.2-fold greater risk of developing breast cancer than those with the Val/Val genotype. Nevertheless, our results did not reveal a significant change in breast cancer risk by MnSOD genotype with alcohol consumption, which is consistent with other studies $(13-15,18,20)$. Similarly, ORs based on three parallel studies $(6,13,23)$ identified a significant association with breast cancer risk for women with a body mass index $\geq 25 \mathrm{~kg} / \mathrm{m}^{2}$. In addition, by combining data from three similar studies $(5,13,14)$, we revealed a higher risk of breast cancer among women who used oral contraceptives and who carried at least one copy of the Ala allele. Mitrunen et al (5) and Egan et al (13) reported markedly elevated ORs for the MnSOD genotype in women who used oral contraceptives. We did not find any significant associations between the MnSOD gene polymorphism and breast cancer risk by different ethnic groups of women with at least 1 copy of the Ala allele for any comparison model.

However, when interpreting the results in the present study several limitations require consideration. Firstly, although the majority of the controls were selected from healthy individuals, specific individuals may have been affected by benign disease. Secondly, the sample sizes for a few of the subgroup analyses were still relatively small. Thirdly, our data were based on unadjusted published estimates; a more precise analysis should be performed to allow for adjustment by other co-variates, including age, family history, environmental factors and other lifestyle factors. Despite these limitations, our meta-analysis also contains strengths, e.g., i) a substantial number of cases and controls were pooled from different studies, resulting in 17,842 subjects, which significantly increased the statistical power of these analyses; ii) no publication biases were detected, indicating that the pooled results may be unbiased.

In conclusion, this meta-analysis suggests that the Ala allele of the MnSOD gene is associated with breast cancer risk among premenopausal women, particularly when combined with certain lifestyle factors. However, it remains necessary to conduct large-sample studies on gene-gene and gene-environment interactions in breast cancer susceptibility by using standardized unbiased genotyping methods, homogeneous breast cancer patients, and sufficiently matched controls to elucidate the effect of the MnSOD polymorphism on breast cancer risk.

\section{Acknowledgements}

This study was supported in part by grants from the National Natural Science Foundation of China (\#30,540,005), the Ministry of Personnel for the High-Level Talent Returned from Overseas [Guo-Ren-Ting-Fa (2005), \#118], the Starting Fund by the Ministry of Education for the Personnel Returning from Abroad [Jiao-Wai-Si-Liu (2008), \#101], and the Funded Projects on the Featured Disciplines (group) in the Institutions of Higher Learning in Hebei Province [Ji-Jiao-Gao (2005) \#52].

\section{References}

1. DeBruin LS and Josephy PD: Perspectives on the chemical etiology of breast cancer. Environ Health Perspect 110: 119-128, 2002.

2. Oberley LW: Mechanism of the tumor suppressive effect of MnSOD overexpression. Biomed Pharmacother 59: 143-148, 2005.

3. Shimoda-Matsubayashi S, Matsumine H, Kobayashi T, Nakagawa-Hattori Y, Shimizu Y and Mizuno Y: Structural dimorphism in the mitochondrial targeting sequence in the human manganese superoxide dismutase gene. Biochem Biophys Res Commun 226: 561-565, 1996.

4. Rosenblum J, Gilula N and Lerner R: On signal sequence polymorphisms and diseases of distribution. Proc Natl Acad Sci USA 93: 4471-4473, 1996.

5. Mitrunen K, Sillanpaa V, Kataja M, Eskelinen M, Kosma VM, Benhamou S, et al: Association between manganese superoxide dismutase (MnSOD) gene polymorphism and breast cancer risk. Carcinogenesis 22: 827-829, 2001. 
6. Cai Q, Shu XO, Wen W, Cheng JR, Dai Q, Gao YT and Zheng W: Genetic polymorphism in the manganese superoxide dismutase gene, antioxidant intake, and breast cancer risk: results from the Shanghai Breast Cancer Study. Breast Cancer Res 6: 647-655, 2004 .

7. Liu G, Zhou W, Park S, Wang LI, Miller DP, Wain JC, et al: The SOD2 Val/Val geotype enhances the risk of nonsmall cell lung carcinoma by p53 and XRCC1 polymorphisms. Cancer 101: $561-565,2004$

8. Hung RJ, Boffetta P, Brennan P, C Malaveille U, Malaveille C, Gelatti U, et al: Genetic polymorphisms of MPO, COMT, MnSOD, NQO1, interactions with environmental exposures and bladder cancer risk. Carcinogenesis 25: 973-978, 2004.

9. Stoehlmacher J, Ingles SA, Park DJ, Zhang W and Lenz HJ: The-9Ala/-9Val polymorphism in the mitochondrial targeting sequence of the manganese superoxide dismutase gene (MnSOD) is associated with age among Hispanics with colorectal carcinoma. Oncol Rep 9: 235-238, 2002.

10. Choi JY, Neuhouser ML, Barnett MJ, Hong CC, Kristal AR, Thornquist MD, et al: Iron intake, oxidative stress-related genes (MnSOD and MPO) and prostate cancer risk in CARET cohort. Carcinogenesis 29: 964-970, 2008.

11. Li H, Kantoff PW, Giovannucci E, Leitzmann MF, Gaziano JM, Stampfer MJ, et al: MnSOD gene polymorphism, prediagnostic antioxidant status, and risk of clinical significant prostate cancer. Cancer Res 65: 2498-2504, 2005.

12. Ambrosone CB, Freudenheim JL, Thompson PA, Bowman E, Vena JE, Marshall JR, et al: Manganese superoxide dismutase (MnSOD) genetic polymorphisms, dietary antioxidants, and risk of breast cancer. Cancer Res 59: 602-606, 1999.

13. Egan KM, Thompson PA, Titus-Ernstoff L, Moore JH and Ambrosone CB: MnSOD polymorphism and breast cancer in a population-based case-control study. Cancer Lett 199: 27-33, 2003.

14. Millikan RC, Player J, De Cotret AR, Moorman P, Pittman G, Vannappagari V,et al: Manganese superoxide dismutase Ala-9Val polymorphism and risk of breast cancer in a population-based case-control study of African Americans and whites. Breast Cancer Res 6: 264-274, 2004.

15. Tamimi RM, Hankinson SE, Spiegelman D, Colditz GA and Hunter DJ: Manganese superoxide dismutase polymorphism, plasma antioxidants, cigarette smoking, and risk of breast cancer. Cancer Epidemiol Biomarkers Prev 13: 989-996, 2004.

16. Bergman M, Ahnstrom M, Palmeba CK, Wegman $P$ and Wingren S: Polymorphism in the manganese superoxidedismutase (MnSOD) gene and risk of breast cancer in young women. J Cancer Res Clin Oncol 131: 439-444, 2005.

17. Cheng TC, Chen ST, Huang CS, Fu YP, Yu JC, Cheng CW, et al: Breast cancer risk associated with genotype polymorphism of the catechol estrogen-metabolizing genes: A multigenic study on cancer susceptibility. Int J Cancer 113: 345-353, 2005.

18. Gaudet MM, Gammon MD, Santella RM, Britton JA, Teitelbaum SL, Eng SM, et al: MnSOD Val-9Ala genotype, pro-and anti-oxidant environmental modifiers, and breast cancer among women on Long Island, New York. Cancer Causes Control 16: 1225-1234, 2005 .

19. Kocabas NA, Sardas S, Cholerton S, Daly AK, Elhan AH and Karakaya AE: Genetic polymorphism of manganese superoxide dismutase (MnSOD) and breast cancer susceptibility. Cell Biochem Funct 23: 73-76, 2005.

20. Slanger TE, Chang-Claude J and Wang-Gohrke S: Manganese superoxide dismutase Ala-9Val polymorphism, environmental modifiers, and risk of breast cancer in a German population. Cancer Causes Control 17: 1025-1031, 2006.
21. Bica CG, Mânica da Cruz IB, de Moura da Silva LL, Toscani NV, Zettler CG and Graudenz MS: Association of manganese superoxide dismutase gene polymorphism (Ala-9Val) and breast cancer in males and females. J Bras Patol Med Lab 43: 219-225, 2007.

22. Bica CG, De Moura da Silva LL, Toscani NV, da Cruz IB, Sá G, Graudenz MS and Zettler CG: MnSOD gene polymorphism association with steroid-dependent cancer. Pathol Oncol Res 15: 19-24, 2009.

23. Eras-ErdoganE, Akbas E, SenliH,Kul S and Colak T: Relationship between polymorphism in the manganese superoxide dismutase gene and breast cancer. Mutat Res 680: 7-11, 2009.

24. Trachootham D, Lu W, Ogasawara MA, Nilsa RD and Huang P: Redox regulation of cell survival. Antioxid Redox Signal 10: 1343-1374, 2008

25. Orrenius S, Gogvadze V and Zhivotovsky B: Mitochondrial oxidative stress: implications for cell death. Annu Rev Pharmacol Toxicol 47: 143-183, 2007.

26. Soini Y, Vakkala M, Kahlos K, Pääkkö P and Kinnula V: MnSOD expression is less frequent in tumour cells of invasive breast carcinomas than in in situ carcinomas or nonneoplastic breast epithelial cells. J Pathol 195: 156-162, 2001.

27. Wang MC, Guo MF and Zhao GQ: Research on mRNA expression level of MnSOD gene in prostate cancer and benign prostatic hyperplasia tissue. Chin J Gerontology 26: 164-165, 2006.

28. Zhou R and Chen P: Expression and significance of MnSOD in non-small cell lung cancer tissues. Chin Modern Medical J 14: 81-84, 2004.

29. Sutton A, Khoury H, Prip-Buus C, Cepanec C, Pessayre D and Degoul F: The Ala16Val genetic dimorphism modulates the import of human manganese superoxide dismutase into rat liver mitochondria. Pharmacogenetics 13: 145-157, 2003.

30. Zhao Y, Xuo Y and Oberley LW: Overexpression of manganese superoxide dismutase suppresses tumor formation by modulation of activator protein-1 signaling in a multistage skin carcinogenesis mode. Cancer Res 61: 6082-6088, 2001.

31. Wang Y, Kuroda M, Gao XS, Asaumi J, Shibuya K, Kawasaki S, et al: Hydrogen peroxide overload increases adriamycininduced apoptosis of $\mathrm{SaOS}(2) \mathrm{FM}$, a manganese superoxide dismutase-overexpressing human osteosarcoma cell line. Int J Oncol 26: 1291-1300, 2005.

32. Komatsu M, Kuroda M, Wang Y, St Clair D, Urano M, Akaki S, Asaumi J, Kawasaki S, Hiraki Y and Kanazawa S: Manganese superoxide dismutase overexpression changes plating efficiency bidirectionally according to change in redox for SaOS2 human osteosarcoma cell line. Int J Oncol 26: 853-862, 2005.

33. Yan T, Oberley LW, Zhong W and St Clair DK: Manganesecontaining superoxide dismutase overexpression causes phenotypic reversion in SV-40 transformed human lung fibroblasts. Cancer Res 56: 2864-2871, 1996.

34. Zwacka RM, Duds L, Epperly MW, Oberley LW, Swanson PE, et al: Increased manganese superoxide dismutase expression suppresses the malignant phenotype of human melanoma cells. Proc Natl Acad Sci USA 90: 3113-3117, 1993.

35. Zhong W and Oberley LW: Suppression of malignant phenotype of human glioma cells by overexpression of manganese superoxide dismutase. Oncogene 14: 481-490, 1997. 